\title{
High spatial resolution photo mosaicking for the monitoring of coralligenous reefs
}

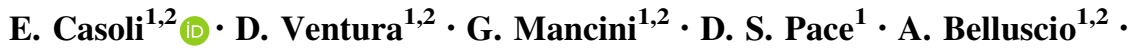 \\ G. Ardizzone $\mathrm{e}^{1,2}$
}

Received: 16 November 2020/ Accepted: 10 June 2021/Published online: 20 June 2021

(C) The Author(s) 2021

\begin{abstract}
Coralligenous reefs are characterized by large bathymetric and spatial distribution, as well as heterogeneity; in shallow environments, they develop mainly on vertical and sub-vertical rocky walls. Mainly diver-based techniques are carried out to gain detailed information on such habitats. Here, we propose a non-destructive and multi-purpose photo mosaicking method to study and monitor coralligenous reefs developing on vertical walls. High-pixel resolution images using three different commercial cameras were acquired on a $10 \mathrm{~m}^{2}$ reef, to compare the effectiveness of photomosaic method to the traditional photoquadrats technique in quantifying the coralligenous assemblage. Results showed very high spatial resolution and accuracy among the photomosaic acquired with different cameras and no significant differences with photoquadrats in assessing the assemblage composition. Despite the large difference in costs of each recording apparatus, little differences emerged from the assemblage characterization: through the analysis of the three photomosaics twelve taxa/morphological categories covered $97-99 \%$ of the sampled surface. Photo mosaicking represents a lowcost method that minimizes the time spent underwater by
\end{abstract}

Topic Editor Stuart Sandin

Supplementary Information The online version contains supplementary material available at https://doi.org/10.1007/s00338021-02136-4.

E. Casoli

edoardo.casoli@uniroma1.it

1 Department of Environmental Biology, Sapienza University of Rome, Piazzale Aldo Moro, 5, 00185 Rome, Italy

2 Centro Interuniversitario Di Biologia Marina Ed Ecologia Applicata, Viale N. Sauro 4, 57128 Livorno, Italy divers and capable of providing new opportunities for further studies on shallow coralligenous reefs.

Keywords Coralligenous reefs · Photomosaic ·

Photoquadrats · Mediterranean Sea · Image stitching

\section{Introduction}

Photography represents an efficient and powerful way to disseminate scientific thoughts and findings both inside and outside the scientific community (Wilder 2009). It also constitutes an objective tool for measuring and describing natural phenomena, reducing human error often affecting in situ observations. In the last thirty years, the number of studies using photography and video as methodologies for data collection has drastically increased in marine science; species, communities, and habitats can be advantageously investigated through these techniques for different scopes (Bicknell et al. 2016; Durden et al. 2016; Bayley and Mogg 2019).

Benthic habitat mapping is a fundamental step for managing and preserving coastal zones, as well as examining unknown environments (Park et al. 2011). Among the underwater domains, there is a strong correlation between the spatial distribution of marine organisms and geomorphological characteristics and features of seabed, especially on hard substrates (e.g., rocky and biogenic environments). In fact, biogenic habitats usually show more diverse geological and biological characteristics compared to sandy nearshore environments (Meadows et al. 2012).

Coralligenous can be considered one of the most important and characteristic ecosystems of the Mediterranean Sea due to biodiversity, productivity, recreational and commercial values. The term coralligenous refers to 
calcareous formations of biogenic origin, characterizing Mediterranean seabed from 15 to $130 \mathrm{~m}$ of depth (Martin et al. 2014; Ingrosso et al. 2018). They are produced primarily by the accumulation of encrusting algae growing in dim light conditions, and secondarily by bio-constructor animals (bryozoans, serpulids, and corals) which help to develop and consolidate the bioconstruction (Ballesteros 2006). Coralligenous platforms and reefs are the two main morphologies described in the literature: The former are built over horizontal sedimentary substrates, the latter develop mainly on vertical rocky substrates located in shallower waters (Ballesteros 2006; Bracchi et al. 2015; SPA/RAC 2019). European directives stress the importance of assessing the ecological quality of coralligenous habitats; as for platforms monitoring is commonly carried out through the use of Remotely Operated Vehicles (ROVs) (Gennaro et al. 2020). Producing high-quality habitat mapping of reefs is not a trivial task because of their irregular bathymetric distribution and morphology which may result in operational constraints during mapping campaigns and sampling surveys.

This aspect is especially true when coralligenous reefs are found on vertical walls and overhangs. In fact, in these complex habitats acoustic (multibeam and side-scan sonar) data derived from ship-based research surveys, ROVs, and Autonomous Underwater Vehicles (AUVs) cannot always provide exhaustive information at community level. In addition, even if the aforementioned remote techniques have been extensively employed to successfully map subhorizontal and deep bioconstructions (Brown et al. 2011; Bonacorsi et al. 2012; Bracchi et al. 2016), these vehicles have high operational costs, and the lack of availability and impracticality of deploying AUVs and ROVs leads many ecologists to rely on images taken by inexpensive and readily available hand-held cameras ( $\mathrm{Li}$ et al. 2019). In fact, on vertical biogenic outcrops, often located in shallower environments, diver-based photographic assessments remain a valuable method for community studies and environmental quality estimation. To date, visual assessment and video-photography are the most diffused sampling methods on coralligenous reefs: They increase the number of samples per survey, facilitate sampling over large spatial and temporal scales, and provide permanent records of the communities under study (Kipson et al. 2011; Zapata-Ramírez et al. 2013; Doxa et al. 2016; Tribot et al. 2016; Cerrano et al. 2019; Valisano et al. 2019). Conversely, the trade-off between making an adequate sampling effort and keeping acceptable safety measures is one of the major constraints associated with divers-based underwater sampling on coralligenous reefs (Parravicini et al. 2010). Undisturbed coralligenous reefs are characterized by high small spatial scale patchiness which implies a considerable minimum sampling effort to characterize the structure of the assemblage at a given site (Kipson et al. 2011; Piazzi et al. 2004, 2016, 2017; Cecchi et al. 2014; Casas-Güell et al. 2016). In this framework, the application of a technique able to provide a detailed view of benthic assemblages with a relative time and cost efficiency will acquire a key role during the acquisition of ecological data and monitoring of such complex environments.

In the past decade, underwater photography techniques and diving equipment have been considerably improved by modern technological advances, leading to large development and spread of digital cameras coupled with a notable improvement in the realm of Computer Vision (e.g., Scale Invariant Feature Transform -SIFT- and Structure from Motion -SfM- algorithms), resulting in new powerful systems for processing underwater images. In particular, visually presenting information of a scene with an unbroken view of the whole region surrounding the observer by using panoramic images can provide to marine ecologists a useful tool to view and navigate underwater landscapes. Furthermore, it contributes to overcoming the light attenuation and backscatter limit imposed underwater. Most of the applications can be divided into two main categories: (1) those attempting to create a consistent continuous image (i.e., a two-dimensional photomosaic), possibly at the expense of minor local distortions; and (2) those aiming at the accurate recovery of three-dimensional information to extract quantitative data about the seafloor, principally based on photogrammetric approaches, which have a substantially higher level of complexity and costs. Two-dimensional photomosaic consists of aligning and stitching several images together with overlapping fields of view (mosaicking), in order to create a single composite high-resolution image (Escartín et al. 2008; Rende et al. 2015). Image stitching algorithms built on feature-based techniques, consists of three main components: image feature extraction (i.e. the process to establish correspondences between points, lines, edges, or other geometric entities to detect corresponding feature points in an image pair), registration (i.e. the process of aligning the images captured from different viewpoints), and blending (i.e. the process applied across the stitch to make both the seams less apparent and to smooth the transition between images). During image registration, image pairs are compared to find the translations that can be used for the alignments of images. After image registration, images are blended to form a single image (Adel et al. 2014). Many feature detectors have been proposed over the years such as SIFT (Lowe 2004), SURF (Bay et al. 2008), FAST (Rosten and Drummond 2006), and ORB (Kulkarni et al. 2013). The well-known SIFT (Scale Invariant Feature Transform) is very robust and exhibits invariance to image translation, rotation, scaling transformations, and good robustness to light changes, noise, and affine transformation (Xing and 
Huang 2010; Zhao et al. 2019). Such features make SIFT a widely used extraction method for feature points from the past 15 years.

Underwater photomosaics derived from open source panorama software such as Microsoft $($ Image Composite Editor (ICE) coupled with Side Scan Sonar acoustic data have proved to be a non-destructive and cost-effective method for ground-truthing in marine habitats mapping (Pergent et al. 2017). Moreover, a panoramic view of the seabed can be also applied to quantify seagrass distribution and abundance improving micro-cartographic analysis (Rende et al. 2015) as well as to accurately map tropical reefs (Judilla et al. 2012) and archeological sites (Vasilijevic et al. 2015).

In this paper, a cost-effective sampling technique based on photomosaics obtained through the image stitching approach for studying coralligenous reefs is introduced and evaluated. Although photogrammetric surveys were carried out on coralligenous reefs to study Axinella cannabina (Esper, 1794), Paramuricea clavata (Risso, 1826), and Corallium rubrum (Linnaeus, 1758) facies (Feral et al. 2014; Palma et al. 2018; Royer et al. 2018), neither tests nor applications of photomosaic technique are currently reported.

Data collected by photomosaics and the most common photoquadrats technique were employed to assess the composition of coralligenous assemblages, and the results were compared to check for potential discrepancies between the two methods. Potential effects on mosaics related to the use of different commercial cameras, representative of different market segments, were also assessed. Finally, the effectiveness of photomosaics, practical and theoretical advantages, opportunities, limitations, and challenges for future researches are discussed.

\section{Material and methods}

\section{Study area}

The study was carried out along the east coast of Giglio Island (central Tyrrhenian Sea, Italy), inside the restricted access area defined after the 2012 Costa Concordia shipwreck and during its salvage operations (Fig. 1). Any touristic or recreational activity (i.e., diving, sailing, and swimming) was forbidden in the wreckage area to avoid any disturbance during the wreck removal phases and to maximize safety in the case of an accident. A brief description of the morphological features and the evolution of the study area is given by Avio et al. (2017), Casoli et al. (2016a, 2017, 2020), Mancini et al (2019), Piazzi et al. (2019a), Regoli et al. (2014), Toniolo et al. (2018).
All the pictures used in this study were acquired along the northern vertical wall of the Gabbianara ridge, between 19 and $25 \mathrm{~m}$ depth, where thick coralligenous reefs are present $(50 \mathrm{~m}$ long $\times 15 \mathrm{~m}$ height approximately). The bioconstruction was impacted by the presence of the wreck and its salvaging operations that caused fine sediment dispersion and the partial loss of benthic organisms (Casoli et al. 2017, 2020; Penna et al. 2018). We decided to test here this new sampling technique in virtue of applying in future to assess the recolonization and the resilience processes on the aforementioned coralligenous reefs.

\section{Data collection}

Several objects of known dimensions were arranged on the reef as references to scale the scene consisting of four ground control points (GPCs, $20 \times 18 \mathrm{~cm}$ ) and one $20 \mathrm{~cm}$ ruler.

Samplings were carried out by scientific scuba divers during late spring of 2019, according to STAR procedure (STAndaRdized coralligenous evaluation procedure; Piazzi et al. 2019b), a standardized protocol for coralligneous reefs monitoring. The divers swam at a low speed of $10-15 \mathrm{~m} / \mathrm{min}$, describing parallel and regularly spaced transect to allow the images overlay, following a boustrophodonic pattern ("mow the lawn" method; Henderson et al. 2013; Burns et al. 2015). Pictures were acquired with a time-lapse of $1 \mathrm{~s}$ at a regular distance of about $50 \mathrm{~cm}$ from the vertical wall, with pure nadiral orientation. Acquisition parameters have been chosen following the best combination described by Marre et al. (2019). The portion of the reefs interested by the investigation covered a surface of $10.21 \mathrm{~m}^{2}$.

Image acquisition for photomosaics construction was carried out using three different cameras which differed in sensors size/pixel resolution and cost: Canon EOS 5D, Sony $\alpha 7-$ III, and GoPro Hero 5 (Table 1). Canon EOS 5D and Sony $\alpha 7$-III settings during image acquisition were kept the same: f/8, shutter speed 1/100 s., and ISO 250. GoPro Hero 5 was used in automatic mode. For all three cameras, the white balance was set in automatic mode and eventually corrected later during image post processing.

All images were stitched into a single, high-resolution image mosaic using Agisoft PhotoScan Professional Edition V. 1.4.0 (Agisoft 2012). It performs 3D reconstruction of objects from images and employs the whole photogrammetric workflow. At the first stage, PhotoScan detects points in the source photos which are stable under viewpoint and lighting variations and generates a descriptor for each point based on its local neighborhood. These descriptors are used later to detect correspondences across the photos. The tie point extraction and detection employ an improved version of SIFT (Chiabrando et al. 2015; 


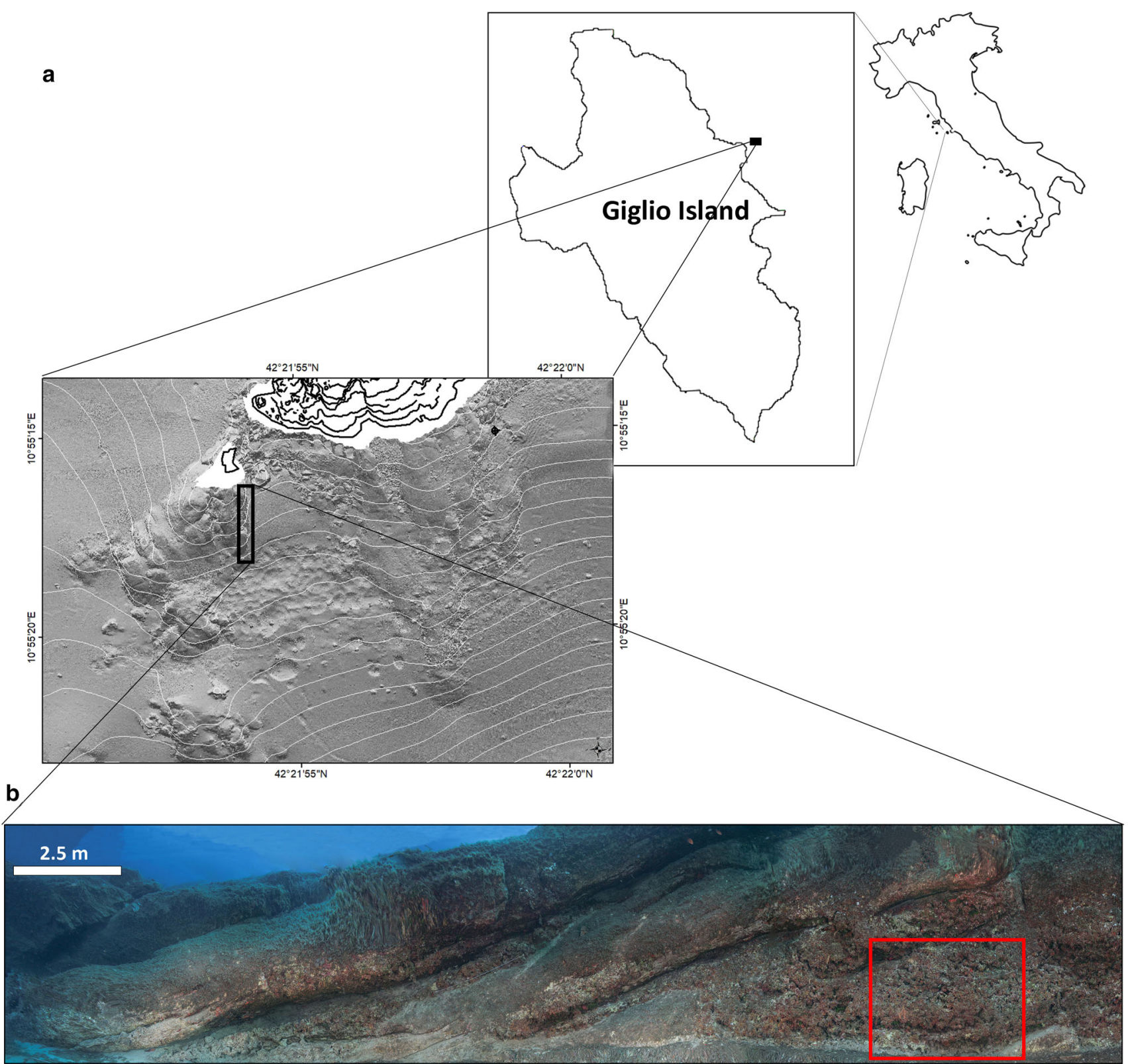

Fig. 1 Location of the study site. Multibeam acquired in 2018 of the restricted area interested by Costa Concordia removal operations (a); photomosaic of the northern vertical wall of the Gabbianara ridge (b) with highlighted in red the portion of coralligenous reef interested by this study

Table 1 Camera models and specs used in this study

\begin{tabular}{|c|c|c|c|c|c|c|c|c|}
\hline Camera type & $\begin{array}{l}\text { Camera } \\
\text { model }\end{array}$ & Sensor (mm) & $\begin{array}{l}\text { Pixel resolution } \\
\text { (Mpixel) }\end{array}$ & Housing & Lens & Light apparatus & $\begin{array}{l}\text { Weight } \\
(\mathrm{kg})\end{array}$ & $\begin{array}{l}\text { Cost } \\
(€)\end{array}$ \\
\hline \multirow[t]{2}{*}{$\begin{array}{l}\text { Full frame professional } \\
\text { cameras }\end{array}$} & $\begin{array}{l}\text { Canon } \\
\text { EOS 5D }\end{array}$ & $\begin{array}{l}\text { CMOS } \\
35.8 \times 23.9\end{array}$ & 12.8 & $\begin{array}{l}\text { Aquatica } \\
\text { digital }\end{array}$ & $15 \mathrm{~mm}$ & INON Z-240 strobes & 4.3 & 3500 \\
\hline & $\begin{array}{l}\text { Sony } \alpha 7- \\
\text { III }\end{array}$ & $35.6 \times 23.8$ & 24.2 & SeaFrogs & $16 \mathrm{~mm}$ & $\begin{array}{l}\text { Scubalamp PV52T } \\
\quad(5000 \mathrm{~lm})\end{array}$ & 2.2 & 2800 \\
\hline Action cam & $\begin{array}{l}\text { GoPro } \\
\text { Hero } 5\end{array}$ & $4.5 \times 6.2$ & 12 & GoPro & $15 \mathrm{~mm}$ & & 0.12 & 450 \\
\hline
\end{tabular}


Murtiyoso et al. 2018). Furthermore, the dense matching method used may be a variant of the Semi-Global Matching (SGM) algorithm. We chose this software because of a user-friendly interface with several simplified functionalities and parameters, which is advantageous for many nonexpert users. It should be noted that we did not focus our work directly on 3D output [e.g., dense point clouds, triangular mesh Models, and Digital Terrain Models (DTMs)], but we used the 2D orthomosaics for digital camera comparison and analysis of the assemblage.

Ten images of a calibration checkboard were acquired underwater for each camera with the same target to lens distance used in the following data acquisition. Subsequently, these images were used for the calibration of optics in Agisoft Lens, a tool implemented by Agisoft package which allowed the estimation of camera calibration parameters, including the non-linear distortion coefficients. These parameters were then inputted into Photoscan as.xml file to speed up pre-calibration steps aimed at removing lens distortion.

To assess the accuracy of the photomosaic and compare it with the commonly used method of photoquadrats (Parravicini et al. 2009; Kipson et al. 2011; Deter et al. 2012; Trygonis and Sini 2012; Piazzi et al. 2017, 2019b), five photographic samples of $0.2 \mathrm{~m}^{2}(50 \times 40 \mathrm{~cm}$, for a total of $1 \mathrm{~m}^{2}$ ) were randomly acquired in the same portion of the reef by Canon EOS 5D (Supplementary materials, Figure S1): The camera was arranged within a PVC frame to minimize parallax error. The distance from the substrate, as well as lighting configuration, was the same used for photomosaic image acquisition. The comparison among methods was made with Canon EOS 5D exclusively, to avoid any difference due to camera and light apparatus.

Photomosaics in.tiff format were imported in ESRI ArcMap 10.2.2, where georeferencing and scaling routine were carried out as follows: two points placed $10 \mathrm{~cm}$ apart, acquired by real-time kinematic (RTK) GPS out of the water in real coordinates (WGS84, UTM fuse $32 \mathrm{~N}$ ) were associated with two points in the photomosaic with the same linear distance $(10 \mathrm{~cm})$, which was measured in the picture by the $20 \mathrm{~cm}$ ruler placed in the scene. This allowed a reference for the scaling routine rather than a correct georeferentiation of the photomosaics: The pixel to distance (pixel/cm) conversion was carried out through the Georeferencing tools in ArcMap. Besides, five photoquadrats $(50 \times 40 \mathrm{~cm})$ were successively over imposed on the Canon photomosaic selecting conspicuous points where control points were added through the specific tool for georeferencing raster images available in ArcGIS. To avoid excessive distortion of raster photoquadrats, we selected a first-order polynomial transformation to transform the raster dataset to the map coordinates. The total error is computed by taking the root mean square (RMS) sum of all the residuals to compute the RMS error. This value describes how consistent the transformation is between the different control points, so we tried to keep this value as close as possible to zero, adding no less than 3 control points. The five photoquadrats used to test the accuracy of the photomosaic were haphazardly distributed on the studied reefs and covered $1 \mathrm{~m}^{2}$ of surface.

\section{Polygon data digitization}

Sessile organisms were identified to the lowest taxonomic level possible allowed by the images. As for conspicuous organisms, the species level was achieved, whereas similar taxa that could not be identified through photographs were aggregated into taxonomical/morphological categories. To assess the composition of coralligenous assemblage in both photomosaics and photoquadrats, polygons were manually outlined by the freehand drawing tool in ArcGIS10.2.2, and then assigned by the user to a specific taxon or morphological category. This method is in use in different image analysis software (Trygonis and Sini 2012). The percentage of substrate surface covered by a given taxa or category (percentage cover, PC) was automatically calculated in ESRI ArcMap 10.2.2 by using Calculate area tool, included in the Spatial statistic toolbox.

\section{Accuracy assessment of photomosaic}

Once the polygon data digitization was complete, the main taxa/morphological categories were identified on both photomosaic and ground-truth data (i.e., photoquadrats) acquired by Canon EOS 5-D. We assessed the accuracy of the taxonomic classification by comparing percentage cover derived from the 5 quadrats cut out of the photomosaic image with manually classified photoquadrats. A confusion matrix was calculated to evaluate the accuracy of the classification made on photomosaic image including: the overall accuracy, which is defined as the proportion of all correctly classified objects and the total sample size; and the Kappa index of agreement (KIA), which is defined as the agreement of the classification results with the corresponding reference data. The proposed categories for the assessment of the classification performance measured by the Kappa value were the following: poor $(\leq 0.1)$, slight (0.1-0.20), fair (0.21-0.40), moderate (0.41-0.60), substantial (0.61-0.80), and excellent $(\geq 0.81)$ (Sim and Wright 2005). Differences in the structure of assemblages were assessed through a one-way multivariate permutational analysis of variance (PERMANOVA). PC data were not transformed in order to stress the importance of the abundance of taxa/morphological categories in determining the differences among Photomosaic and Photoquadrats (Methods, as fixed factors). 


\section{Cameras comparison}

The number of taxa/morphological categories $(N)$ and PC were, respectively, counted and measured in each photomosaic to compare the three cameras used in the study. The assessments were carried out separately in each photomosaic by a single observer, to avoid any analyst effect. Furthermore, the number of patches (NP) was counted in each photomosaic, where a patch was defined as a surface covered by specific taxa/morphological category well distinguished from the surrounding organisms. Taxa/morphological categories with no distinctive and recognizable borders (i.e., largely diffused crustose algae and sediment) were excluded from this analysis. The three parameters were assessed by ESRI ArcMap 10.2.2. Then, the three photomosaics were divided into 9 sub-samples, and the differences in terms of NP among cameras were tested through a one-way multivariate PERMANOVA. Furthermore, pairwise tests were used to discriminate among cameras. A similarity percentage-species contribution analysis (SIMPER) was carried out to identify the taxa/morphological categories that mostly contributed to the dissimilarity among cameras.

\section{Results}

Analyses were carried out on a portion of coralligenous reef measuring $10.21 \mathrm{~m}^{2}$ surface area. The number of pictures acquired by each camera and used to build the three photomosaics ranged from 110 to 120 . The three mosaics had a very high resolution, $0.36 \mathrm{~mm} / \mathrm{pixel}$, $0.21 \mathrm{~mm} / \mathrm{pixel}$, and $0.50 \mathrm{~mm} / \mathrm{pixel}$, for Canon EOS 5D, Sony $\alpha 7$-III, and GoPro Hero 5, respectively (Supplementary materials, Figure S2). The features of the cameras utilized during the study are summarized in Table 1.

\section{Method comparison}

Accuracy assessment carried out on the mosaic derived from Canon EOS-5D imagery showed high fidelity in class identification when compared to the five ground-truth photoquadrats with average overall accuracy and KIA value of $76.49 \%( \pm 10.76 \mathrm{SD})$ and $0.71( \pm 0.15 \mathrm{SD})$, respectively. Major errors were due both to the largest (e.g., Peyssonnelia spp.) and most variable (Pseudochlorodesmis furcellata, mucilage, Reteporella grimaldii) taxa/categories which often obscured smaller categories, such as serpulids or erect ascidians (Halocinthia papillosa), leading to category-cover misclassification.

No significant differences in the composition of the assemblage were found among photomosaic and photoquadrats methods (Table 2). The analysis of the five
Table 2 Summary of permutational multivariate analysis of variance (PERMANOVA) results for structure of assemblages described by among photomosaic and photoquadrats methods

\begin{tabular}{llllll}
\hline Source & df & S.S & M.S & Pseudo-F & $P$ \\
\hline Method & 1 & 0.005 & 0.005 & 0.240 & 0.851 \\
Residual & 8 & 0.189 & 0.023 & & \\
\hline
\end{tabular}

replicates acquired by photomosaic and photoquadrats methods allowed the identification of 27 taxa/morphological categories of the total amount of 33 taxa/morphological categories identified on the whole study area: percentage cover (PC) measured in the five photomosaics and photoquadrats replicates showed an overall similar pattern (Fig. 2).

\section{Assemblage assessment through photomosaics}

Thirty-three taxa/morphological categories were identified and mapped by Canon photomosaic, followed by Sony $(N=31)$ and GoPro $(N=27)$ photomosaics.

The assemblages assessed through the three photomosaics were overall similar (Fig. 3). Twelve taxa accounted for the $97.2 \%, 97.7 \%$, and $99.0 \%$ of percentage cover (PC), in Canon, Sony, and GoPro, respectively, whereas twentyone taxa showed PC less than $0.6 \%$ when present (supplementary materials, Tab. S1). Algae, bare surfaces, and sediment characterized the coralligenous reef of the studied site. The most common algal taxa were: Peyssonnelia spp., P. furcellata, mucilage, Palmophyllum crassum, and Flabellia petiolata. As for benthic invertebrates, exclusively $R$. grimaldii and Eunicella cavolini showed PC higher than $1 \%$. The other taxa were quite rare or scarcely reported in the study area. In particular, small erect bryozoans, Ceramiales (erect red algae), articulated Corallinales, and the bryozoan Margaretta cereoides were not reported in GoPro photomosaic, whereas solitary corals and boring sponges were absent in both Sony and GoPro photomosaics.

The number of patches (NP) significantly differed among cameras (Table 3, Fig. 4); pairwise test highlighted that these differences were between Canon and GoPro cameras. Serpulids, encrusting bryozoans, $F$. petiolata, $R$. grimaldii, $P$. crassum, mucilage, and encrusting sponges were the taxa/morphological categories responsible for the dissimilarity between cameras (SIMPER analyses, Supplementary Materials Table SXX). Considering that PC values described similar assemblages, small patches were mostly responsible for the differences here described. 


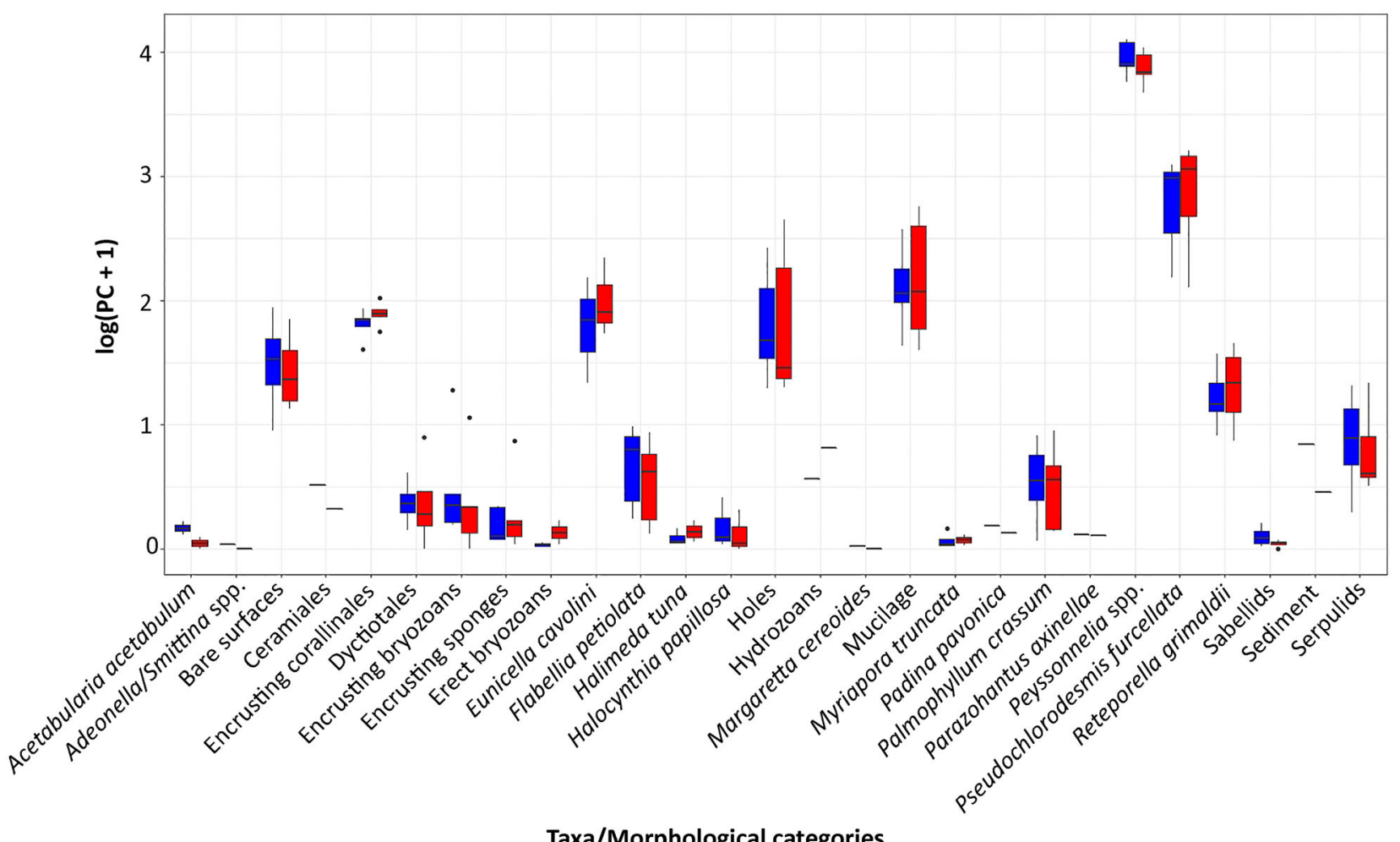

Fig. 2 Percentage cover (PC) of the taxa/morphological categories compared among photomosaic (blue) and photoquadrats (red). Data have been $\log$-transformed for visual representation

\section{Discussion}

Image mosaicking represents an multi-purpose and lowcost technique to survey and sample coralligenous reefs. It offers new perspectives to study the diversity, ecological status, dynamic processes, growth, and competition phenomena occurring in one of the most important Mediterranean bioconstructions. The combination of large-scale images (tens of $\mathrm{m}^{2}$ ) and high-resolution benthic information (sub-centimeter scale) is the main advantage of photomosaic technique. This perfectly copes with coralligenous reefs features, such as small scale spatial heterogeneity due to the patchy distribution of species (Ferdeghini et al. 2000; Piazzi et al. 2004), high diversity, minimum sampling effort (Kipson et al. 2011), presence of both large colonial and small organisms (Casoli et al. 2016b; Sini et al. 2019). Larger size of sampling unit increases advantages in using digital photography as sampling method by reducing bias errors and producing similar results to those obtained by visual assessment (VA) (Parravicini et al. 2009). Furthermore, permanent high-quality records of the seafloor allow the application/replication of measures through different data extraction techniques, according to researchers' needs (i.e., accuracy, resolution, time). In the present study, we carried out percentage cover estimation by image analysis (manual drawn), but also other data extraction techniques could be performed, such as VA, frequency of occurrence, and point-intercept transects (Van Rein et al. 2012).

The performance of photomosaic and photoquadrat techniques was not significantly different. The high precision, highlighted by overall accuracy and KIA, reveals that photomosaic is consistent with the photographic-based methods commonly used to study coralligenous reefs. Therefore, sub-sampling the large areas covered by photomosaics can be useful for the application of the most common indexes assessing the ecological quality of coralligenous habitats (Deter et al. 2012; Gatti et al. 2015; Ferrigno et al. 2017; Montefalcone et al. 2017; Piazzi et al. 2017; Sartoretto et al. 2017). Another feature of this method is the possibility to identify changes at the landscape level, repeating observations on the same portion of the seabed. Avoiding the deploying of several permanent markers or plots as for the photoquadrats method (Garrabou et al. 2002; García-Gómez et al. 2020) may allow minimizing the disturbance in community dynamic studies. The advantages and disadvantages of the two methods were summarized in Table 4. Both the methods represent cost-effective sampling strategies, with costs varying according to the camera model and light apparatus used. The comparison among three cameras showed high precision in the description of the coralligenous assemblage, 


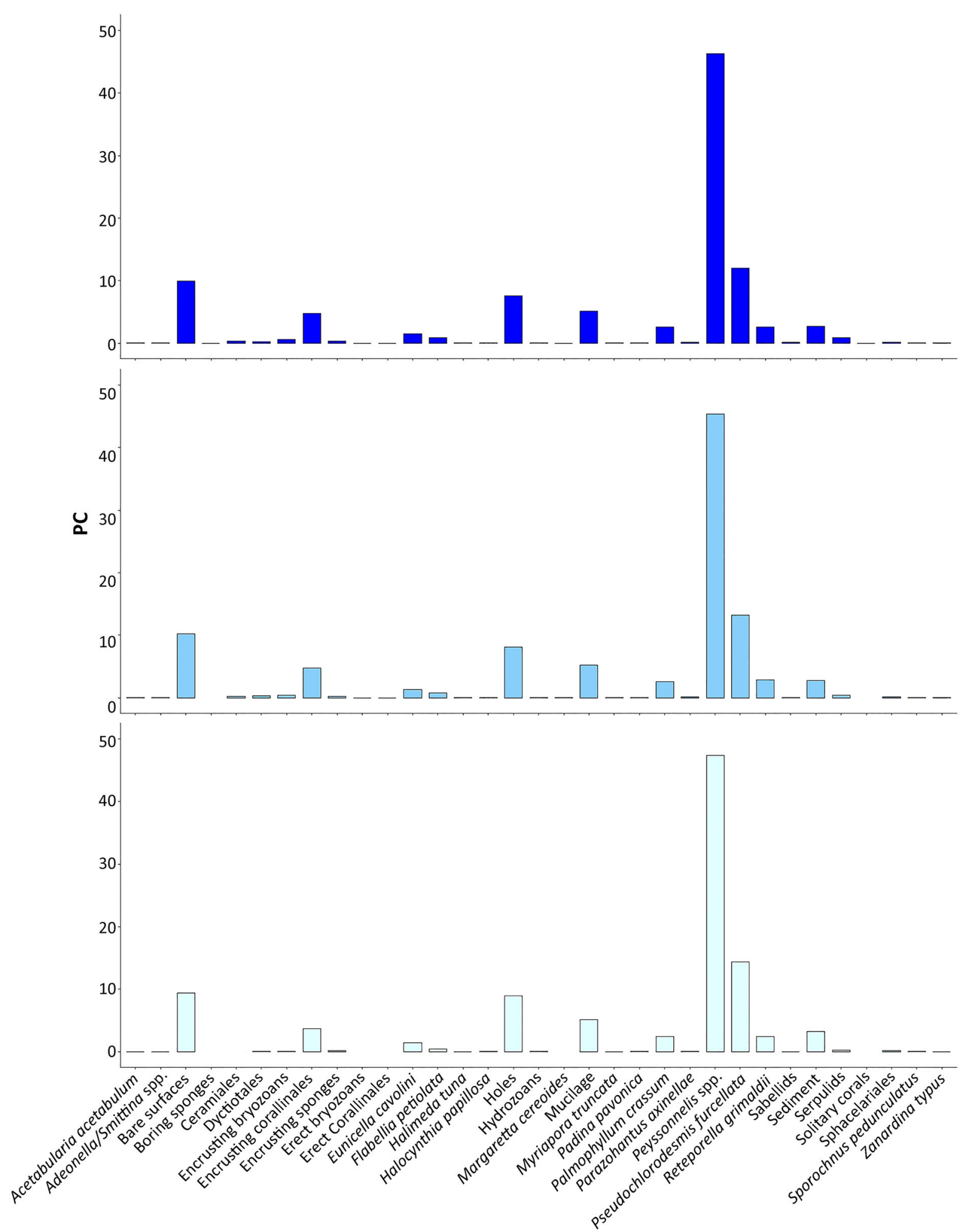

Taxa/Morphological categories

Fig. 3 Percentage cover (PC) of the taxa/morphological categories recorded in each of the three photomosaics: Canon (blue), Sony (light blue), and GoPro (cyan) 
thus supporting the suitability of low-cost cameras, as well. Nevertheless, differences were reported for low abundant or scattered taxa/categories, exclusively. The GoPro Hero 5 showed lower accuracy than Canon EOS 5D for both composition and abundance of taxa: camera features and light apparatus were the main drivers of the reported differences. Blurry pictures could have influenced the

Table 3 Results of PERMANOVA and pairwise tests on NP counted in the three photomosaic sub-samples. Significant values are highlighted in bold

\begin{tabular}{llllll}
\hline Source & df & S.S & M.S & Pseudo-F & $P$ \\
\hline Cameras & 2 & 0.857 & 0.428 & 4.479 & $\mathbf{0 . 0 0 1}$ \\
Residuals & 24 & 2.296 & 0.095 & & \\
\hline
\end{tabular}

Pairwise test comparison (Cameras)

\begin{tabular}{llll}
\hline Pairs & $F$ & $\begin{array}{l}p- \\
\text { value }\end{array}$ & $\begin{array}{l}\text { adj. } p- \\
\text { value }\end{array}$ \\
\hline Canon-Sony & 1.847 & 0.080 & 0.240 \\
Canon- & 4.387 & 0.009 & $\mathbf{0 . 0 2 7}$ \\
$\quad \begin{array}{l}\text { GoPro } \\
\text { Sony-GoPro }\end{array}$ & 1.797 & 0.109 & 0.327 \\
\hline
\end{tabular}

identification of smaller organisms. On the other hand, differences among Sony $\alpha 7-$ III and Canon EOS 5D may be attributable to light, even though results were not consistent with the camera resolution (24.2 Mpixel and 12.8 Mpixel, respectively): strobes provide more power and higher angle of coverage. It produced an increase in PC of holes in both GoPro and Sony $(8.92 \%$ and $8.16 \%$, respectively) if compared to Canon (7.63\%), and the resulting classification of darkening areas as cavities instead of benthic organisms. The use of an appropriate illumination system is pivotal to avoid loss of information of smaller or cryptic species.

The slight differences among camera models can also be explained in terms of camera orientation, which is one of the most important parameters affecting reprojection errors. According to Marre et al. (2019), a pure nadiral orientation was used during image acquisition given the best results in their methodological study. In the case of more complex environments such as coralligenous reefs, details in holes, crevices, and overhang can be lost without acquiring oblique images. Nevertheless, the camera orientation was set according to the aim of the study that was to create a two-dimensional photomosaic of the coralligenous wall and not a three-dimensional photogrammetric model of horizontal surfaces using SfM routine (Enochs et al.

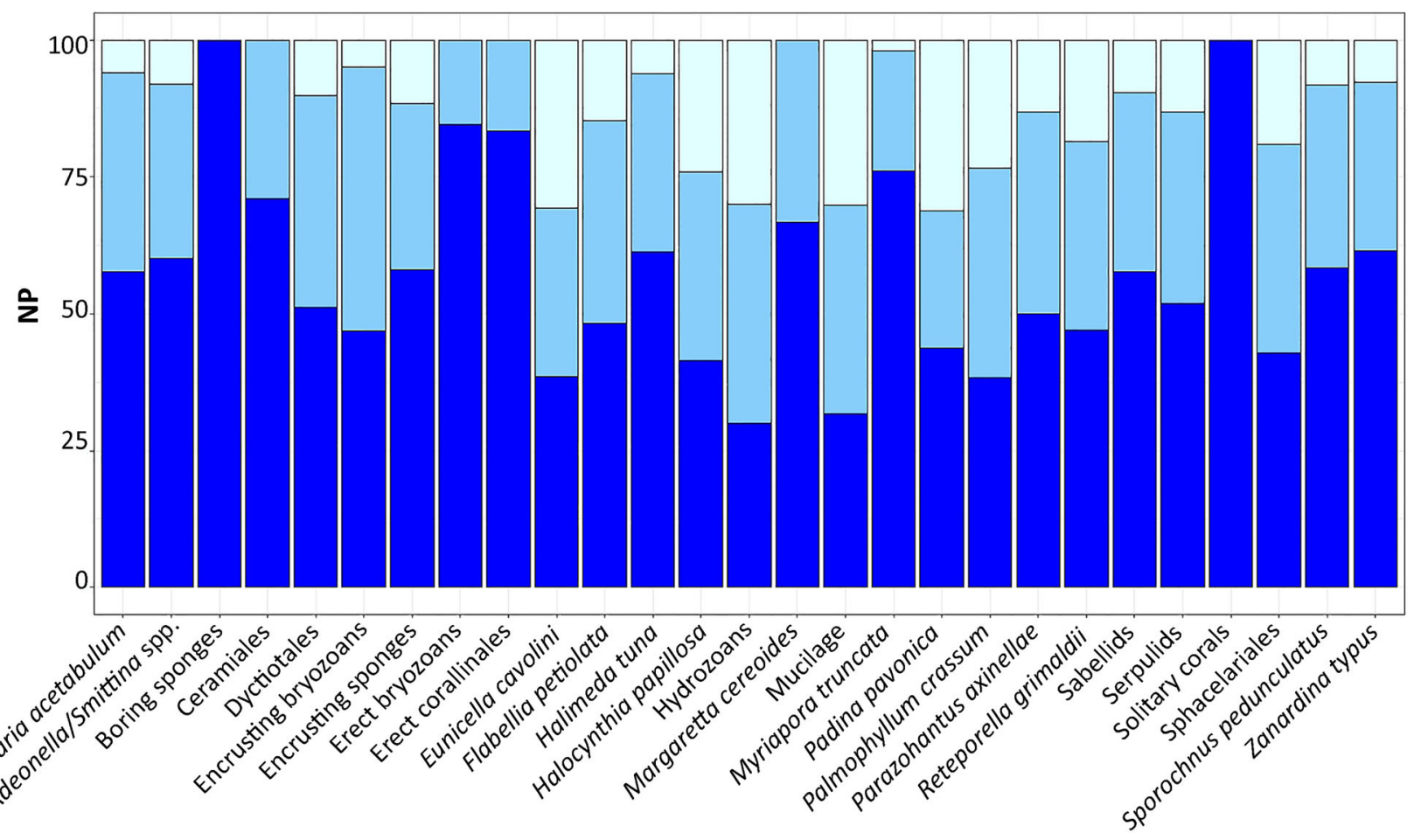

Taxa/Morphological categories

Fig. 4 NP (number of patches) of taxa/morphological categories counted in each photomosaic. Data are reported as percentage of the total number of patches of each taxon/morphological category for a better visual representation smoothing differences among taxa/morphological categories. Colors assigned according to the camera have been maintained the same in Fig. 4: Canon (blue), Sony (light blue), and GoPro (cyan) 
Table 4 Pros $(\boldsymbol{})$ and cons $(\boldsymbol{X})$ of applying photomosaics and photoquadrats as sampling methods for coralligenous reefs investigations

\begin{tabular}{|c|c|c|}
\hline & Photomosaic & Photoquadrats \\
\hline Cost-effective & $\checkmark$ & $\checkmark$ \\
\hline High-resolution benthic information & $\checkmark$ & $\checkmark$ \\
\hline Large-scale images & $\checkmark$ & $x$ \\
\hline Application of different data extraction techniques & $\checkmark$ & $x$ \\
\hline From species to landscape investigations & $\checkmark$ & $x$ \\
\hline Georeferentiation & $\boldsymbol{V}$ (horizontal seafloors) & $x$ \\
\hline Application of ecological indexes & $\checkmark$ & $\boldsymbol{V}$ \\
\hline Image analysis effort & $x$ & $\checkmark$ \\
\hline
\end{tabular}

2015; Palma et al. 2018, 2019; Royer et al. 2018; Marre et al. 2019, 2020a; Ventura et al. 2021). One of the main limitations of the proposed method is the impossibility of absolutely georeferencing of points on the vertical seafloor by using classical ground control points (GCPs), in which real coordinates are usually estimated for the three axes ( $x$, $y$, and $z$ ) with a high degree of accuracy (in the order of $\mathrm{mm}$ with professional-grade GNSS systems during aerial campaigns). The use of marker buoys, which would have allowed the position of the sampling area in the real space and the collection of the positions of reference points from the surface, cannot be achieved due to currents and depth which often characterize infralittoral sciaphilous assemblages on coralligenous outcrops. Despite the high cost, the georeferencing of points on the vertical seafloor can be carried out through forward-looking Multi Beam Echo Sounder (MBES) from ROVs which would allow a traditional photogrammetric approach: such method was efficiently applied in deep waters to achieve terrain descriptors and map species distribution on full vertical environments (Huvenne et al. 2011; Robert et al. 2017).

The multi-purpose features of the photo mosaicking technique and the possibility to observe the same surface over time are particularly well-adapted to assess the recolonization and dynamic process occurring on coralligenous reefs characterized by bare surfaces. The operation aimed at stabilizing the bottom where the wreck of Costa Concordia caused fine sediment release in both 2013 and 2014 (Casoli et al. 2017), which partially buried the basal portion of the studied bioconstruction. From January 2015 to April 2018, the seafloor of the restricted area was cleaned by the disturbances derived from the wreck removal (Remediation phase): A total of $25,000 \mathrm{t}$ of sediment were removed. As a consequence of the sediment removal, dead portions of coralligenous reefs were revealed (Fig. 5), likewise the sediment-exposed terrace described after exceptional stormy events (Teixidó et al. 2013; Betti et al. 2020). Such bare surfaces represent unique substrates to study the natural recovery of coralligenous reefs: The application of photomosaic technique

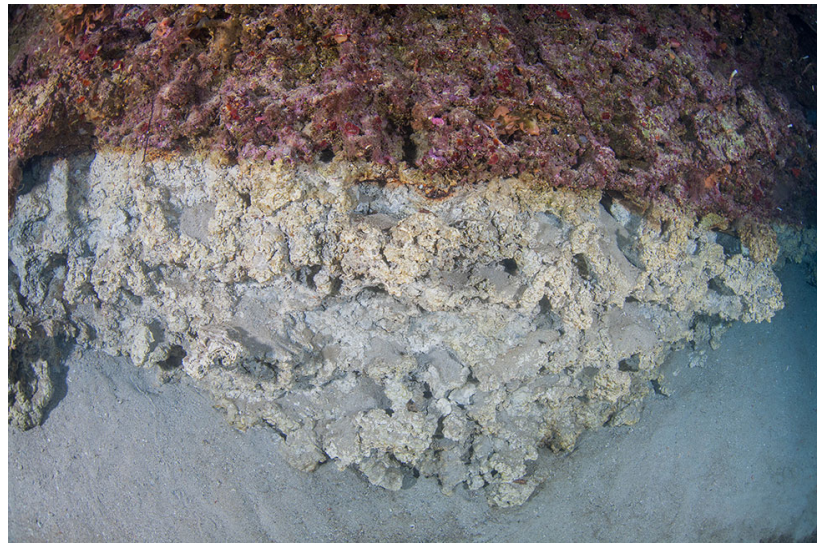

Fig. 5 The dead part of concretion at the bottom of coralligenous reefs revealed after the sediment removal. The boundary between living bioconstruction and bare surfaces indicated the burial level

will help to comprehend the community succession patterns.

Photomosaic represents a safe technique up to $40 \mathrm{~m}$ depth: On average, $8 \pm 3 \mathrm{~min}$ were necessary to cover areas of approximately $10 \mathrm{~m}^{2}$ characterized by high resolution, as described in this study. Such average was timed in a total of 9 preparatory data acquisition, included the three photomosaics used in the present work. Photomosaic surveys can be efficiently applied to cover large surfaces up to $40 \mathrm{~m}$ depth while remaining within the safety curve (Fig. 6; Casoli, unpublished data). The recent progress in technical dive, as well as the use of Close Circuit Underwater Breathing Apparatus (CCUBA; i.e., rebreather), if coupled with photomosaic might contribute to further increase the size of the sampling area. In light of increasing divers' safety, the application of AUVs or ROVs technologies might represent a step forward, including georeferenced pictures, no depth-related constraints, and considerably increasing the investigated area. Besides species distribution in deep or inaccessible environments, vertical structures (Robert et al. 2017). On the contrary, limitations in the use of AUVs or ROVs systems for shallow coastal habitats studies are represented by their they allow accurate reconstruction of seafloor features on 
Fig. 6 The number of photomosaic replicates (surface of $10 \mathrm{~m}^{2}$ each one) that can be acquired at different depths without decompression stops. The blue line indicates the safety curve for nodecompression dives (US Navy safety curve). Each of the black dots indicates the mean $\pm \mathrm{SD}$ time $(8 \pm 3 \mathrm{~min})$ to acquire pictures from an area of $10 \mathrm{~m}^{2}$

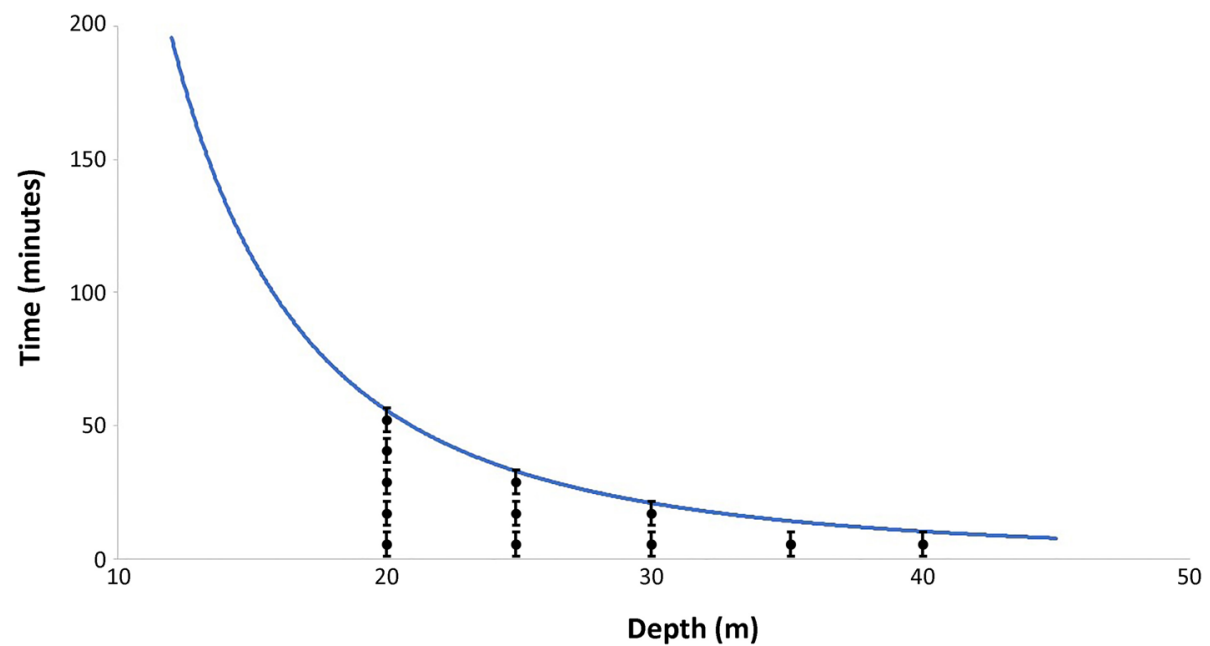

challenging costs and maneuverability issues; seabed complexity and presence of vertical walls might impact the outcome other than the recovery of the AUVs.

The time required for image processing and alignment was about $1 \mathrm{~h}$ for each photomosaic, according to time reported by Palma et al. (2018) and Marre et al. (2019). On the contrary, the most time-consuming step was image analysis which required $>6 \mathrm{~h}$. It depended on the accuracy and resolution of the process itself, but it could drastically vary depending upon data extraction techniques. The implementation of an automated benthic species identification for coralligenous reefs will drastically reduce such time-consuming analyses, allowing to minimize limits related to this tool (Chirayath and Li 2019; Williams et al. 2019; Marre et al. 2020b).

Technology advances support the researchers to easily and efficiently recognize ecological processes and changes in the marine environment. This study outlined an accurate, reproducible, and cost-effective method to study and monitor coralligenous communities at different depths reached by SCUBA divers. The multi-purpose features of photomosaic allow different investigations, from species to seascape level. In particular, this method could be applied to assess the effects of both climate anomalies and human disturbances effects on protected habitats, such as coralligenous reefs, through the definition of fixed monitoring stations. The photomosaic method improves the opportunity of collection of field data, not excluding standard sampling procedures or the application of indexes aimed to assess the ecological quality of the investigated communities.

Acknowledgements We would like to thank Max Shark Diving for boat support during fieldwork.

Funding Open access funding provided by Università degli Studi di Roma La Sapienza within the CRUI-CARE Agreement.

\section{Declarations}

Conflict interest All the authors, as scientists of the Sapienza University of Rome and CIBM, were commissioned by the TitanMicoperi group and Costa Crociere S.p.A. to assess the environmental risks of engineering operations and to monitor the environmental conditions in the impacted areas in order to protect marine habitats during the salvage of the Concordia wreck. The authors' work was controlled and continuously shared with an Italian governmental body (The 'Osservatorio'), which fulfilled the public function of verifying the performance of the monitoring.

Open Access This article is licensed under a Creative Commons Attribution 4.0 International License, which permits use, sharing, adaptation, distribution and reproduction in any medium or format, as long as you give appropriate credit to the original author(s) and the source, provide a link to the Creative Commons licence, and indicate if changes were made. The images or other third party material in this article are included in the article's Creative Commons licence, unless indicated otherwise in a credit line to the material. If material is not included in the article's Creative Commons licence and your intended use is not permitted by statutory regulation or exceeds the permitted use, you will need to obtain permission directly from the copyright holder. To view a copy of this licence, visit http://creativecommons. org/licenses/by/4.0/.

\section{References}

Adel E, Elmogy M, Elbakry H (2014) Image stitching based on feature extraction techniques: a survey. Int $\mathbf{J}$ Comput Appl 99:1-8. https://doi.org/10.5120/17374-7818

Agisoft (2012) Agisoft PhotoScan User Manual - Professional Edition, Version 0.9.0.

Avio CG, Cardelli LR, Gorbi S, Pellegrini D, Regoli F (2017) Microplastics pollution after the removal of the Costa Concordia wreck: First evidences from a biomonitoring case study. Environ Pollut 227:207-214. https://doi.org/10.1016/j.envpol.2017.04. 066

Ballesteros E (2006) Mediterranean coralligenous assemblages: a synthesis of present knowledge. Oceanogr Mar Biol an Annu Rev 44:123-195 
Bay H, Ess A, Tuytelaars T, Van Gool L (2008) Speeded-up robust features (SURF). Comput vis Image Underst 110:346-359

Bayley DTI, Mogg AOM (2019) New advances in benthic monitoring technology and methodology. In: Sheppard, C. (Ed.) World seas: An environmental evaluation. Academic Press, pp 121-132. https://doi.org/10.1016/B978-0-12-805052-1.00006-1

Betti F, Bavestrello G, Bo M, Enrichetti F, Cattaneo-Vietti R (2020) Effects of the 2018 exceptional storm on the Paramuricea clavata (Anthozoa, Octocorallia) population of the Portofino Promontory (Mediterranean Sea). Reg Stud Mar Sci 34:101037. https://doi.org/10.1016/j.rsma.2019.101037

Bicknell AWJ, Godley BJ, Sheehan EV, Votier SC, Witt MJ (2016) Camera technology for monitoring marine biodiversity and human impact. Front Ecol Environ 14:424-432. https://doi.org/ 10.1002/fee. 1322

Bonacorsi M, Pergent-Martini C, Clabaut P, Pergent G (2012) Coralligenous "atolls": discovery of a new morphotype in the Western Mediterranean Sea. Comptes Rendus - Biol 335:668-672. https://doi.org/10.1016/j.crvi.2012.10.005

Bracchi VA, Nalin R, Basso D (2016) Morpho-structural heterogeneity of shallow-water coralligenous in a Pleistocene marine terrace (Le Castella, Italy). Palaeogeogr Palaeoclimatol Palaeoecol 454:101-112. https://doi.org/10.1016/j.palaeo.2016.04.014

Bracchi VA, Savini A, Marchese F, Palamara S, Basso D, Corselli C (2015) Coralligenous habitat in the Mediterranean Sea: A geomorphological description from remote data. Ital J Geosci 134:32-40. https://doi.org/10.3301/IJG.2014.16

Brown CJ, Smith SJ, Lawton P, Anderson JT (2011) Benthic habitat mapping: A review of progress towards improved understanding of the spatial ecology of the seafloor using acoustic techniques. Estuar Coast Shelf Sci 92:502-520

Burns JHR, Delparte D, Gates RD, Takabayashi M (2015) Integrating structure-from-motion photogrammetry with geospatial software as a novel technique for quantifying $3 \mathrm{D}$ ecological characteristics of coral reefs. PeerJ 3:e1077

Casas-Güell E, Cebrian E, Garrabou J, Ledoux J-B, Linares C, Teixidó N (2016) Structure and biodiversity of coralligenous assemblages dominated by the precious red coral Corallium rubrum over broad spatial scales. Sci Rep 6:36535. https://doi. org/10.1038/srep36535

Casoli E, Bonifazi A, Ardizzone G, Gravina MF (2016) How algae influence sessile marine organisms: The tube worms case of study. Estuar Coast Shelf Sci 178:12-20. https://doi.org/10.1016/ j.ecss.2016.05.017

Casoli E, Mancini G, Ventura D, Pace DS, Belluscio A, Ardizzone GD (2020) Reteporella spp. success in the re-colonization of bare coralligenous reefs impacted by Costa Concordia shipwreck: The pioneer species you did not expect. Mar Poll Bull 161: 111808. https://doi.org/10.1016/j.marpolbul.2020.11180

Casoli E, Ventura D, Modica MV, Belluscio A, Capello M, Oliverio M, Ardizzone GD (2016) A massive ingression of the alien species Mytilus edulis L. (Bivalvia: Mollusca) into the Mediterranean Sea following the Costa Concordia cruise-ship disaster. Mediterr Mar Sci 17:404-416

Casoli E, Ventura D, Cutroneo L, Capello M, Jona-Lasinio G, Rinaldi R, Criscoli A, Belluscio A, Ardizzone GD (2017) Assessment of the impact of salvaging the Costa Concordia wreck on the deep coralligenous habitats. Ecol Indic 80:124-134. https://doi.org/10. 1016/j.ecolind.2017.04.058

Cecchi E, Gennaro P, Piazzi L, Ricevuto E, Serena F (2014) Development of a new biotic index for ecological status assessment of Italian coastal waters based on coralligenous macroalgal assemblages. Eur J Phycol 49(3):37-41. https://doi. org/10.1080/09670262.2014.918657

Cerrano C, Bastari A, Calcinai B, Di Camillo C, Pica D, Puce S, Valisano L, Torsani F (2019) Temperate mesophotic ecosystems: gaps and perspectives of an emerging conservation challenge for the Mediterranean Sea. Eur Zool J 86:370-388. https://doi.org/10.1080/24750263.2019.1677790

Chiabrando F, Donadio E, Rinaudo F (2015) SfM for orthophoto to generation: a winning approach for cultural heritage knowledge. Int Arch Photogramm Remote Sens Spat Inf Sci 40(5):91

Chirayath V, Li A (2019) Next-Generation Optical Sensing Technologies for Exploring Ocean Worlds-NASA FluidCam, MiDAR, and NeMO-Net. Front Mar Sci 6:521

Deter J, Descamp P, Ballesta L, Boissery P, Holon F (2012) A preliminary study toward an index based on coralligenous assemblages for the ecological status assessment of Mediterranean French coastal waters. Ecol Indic 20:345-352. https://doi. org/10.1016/j.ecolind.2012.03.001

Doxa A, Holon F, Deter J, Villéger S, Boissery P, Mouquet N (2016) Mapping biodiversity in three-dimensions challenges marine conservation strategies: The example of coralligenous assemblages in North-Western Mediterranean Sea. Ecol Indic 61:1042-1054. https://doi.org/10.1016/j.ecolind.2015.10.062

Durden JM, Schoening T, Althaus F, Friedman A, Garcia R, Glover AG, Greinert J, Stout NJ, Jones D, Jordt A, Kaeli J, Köser K, Kuhnz L, Lindsay D, Morris K, Nattkemper T, Osterloff J, Ruhl H, Singh H, Tran M, Bett B (2016) Perspectives in visual imaging for marine biology and ecology: From acquisition to understanding. Oceanogr Mar Biol An Annu. Rev 54:1-72. https://doi.org/10.1201/9781315368597-2

Enochs IC, Manzello DP, Donham EM, Kolodziej G, Okano R, Johnston L, Young C, Iguel J, Edwards CB, Fox MD, Valentino L, Johnson S, Benavente D, Clark SJ, Carlton R, Burton T, Eynaud Y, Price NN (2015) Shift from coral to macroalgae dominance on a volcanically acidified reef. Nat Clim Chang 5:1083-1088. https://doi.org/10.1038/nclimate2758

Escartín J, García R, Delaunoy O, Ferrer J, Gracias N, Elibol A, Cufi X, Neumann L, Fornari DJ, Humphris SE, Renard J (2008) Globally aligned photomosaic of the Lucky Strike hydrothermal vent field (Mid-Atlantic Ridge, $37^{\circ} 18.5^{\prime} \mathrm{N}$ ): Release of georeferenced data, mosaic construction, and viewing software. Geochemistry Geophys Geosystems 9:1-17. https://doi.org/10. 1029/2008GC002204

Féral JP, Arvanitidis C, Chenuil A, Çinar ME, David R, Egea E, Sartoretto S (2014) CIGESMED: Coralligenous based indicators to evaluate and monitor the 'Good Environmental Status' of the Mediterranean coastal waters, a SeasEra project. Proceedings of the second Mediterranean Symposium on the conservation of Coralligenous and other Calcareous Bio-Concretions. UNEP/ MAP-RAC/SPA publ., Portorož (Slovenia), pp 15-21,

Ferdeghini F, Acunto S, Cocito S, Cinelli F (2000) Variability at different spatial scales of a coralligenous assemblage at Giannutri Island (Tuscan Archipelago, northwest Mediterranean). Hydrobiologia 440:27-36. https://doi.org/10.1023/A: 1004124423718

Ferrigno F, Russo GF, Sandulli R (2017) Coralligenous Bioconstructions Quality Index (CBQI): A synthetic indicator to assess the status of different types of coralligenous habitats. Ecol Indic 82:271-279. https://doi.org/10.1016/j.ecolind.2017.07.020

García-Gómez JC, González AR, Maestre MJ, Espinosa F (2020) Detect coastal disturbances and climate change effects in coralligenous community through sentinel stations. PloS One 15(5):e0231641. https://doi.org/10.1371/journal.pone.0231641

Garrabou J, Ballesteros E, Zabala M (2002) Structure and dynamics of North-Western Mediterranean rocky benthic communities along a depth gradient. Estuar Coast Shelf Sci 55:493-508. https://doi.org/10.1006/ecss.2001.0920

Gatti G, Bianchi CN, Morri C, Montefalcone M, Sartoretto S (2015) Coralligenous reefs state along anthropized coasts: Application and validation of the COARSE index, based on a rapid visual 
assessment (RVA) approach. Ecol Indic 52:567-576. https://doi. org/10.1016/j.ecolind.2014.12.026

Gennaro P, Piazzi L, Cecchi E, Montefalcone M, Morri C, Bianchi CN (2020) Monitoraggio e valutazione dello stato ecologico dell'habitat a coralligeno. Il coralligeno di parete. ISPRA, Manuali e Linee Guida n.191/2020

Henderson J, Pizarro O, Johnson-Roberson M, Mahon I (2013) Mapping submerged archaeological sites using stereo-vision photogrammetry. Int J Naut Archaeol 42(2):243-256

Huvenne VAI, Tyler PA, Masson DG, Fisher EH, Hauton C, Hühnerbach V, Bas TP, Wolff GA (2011) A picture on the wall: Innovative mapping reveals cold-water coral refuge in submarine canyon. PLoS One 6:1-9. https://doi.org/10.1371/ journal.pone. 0028755

Ingrosso G, Abbiati M, Badalamenti F, Bavestrello G, Belmonte G, Cannas R, Benedetti-Cecchi L, Bertolino M, Bevilacqua S, Bianchi CN, Bo M, Boscari E, Cardone F, Cattaneo-Vietti R, Cau A, Cerrano C, Chemello R, Chimienti G, Congiu L, Corriero G, Costantini F, De Leo F, Donnarumma L, Falace A, Fraschetti S, Giangrande A, Gravina MF, Guarnieri G, Mastrototaro F, Milazzo M, Morri C, Musco L, Pezzolesi L, Piraino S, Prada F, Ponti M, Rindi F, Russo GF, Sandulli R, Villamor A, Zane L, Boero F (2018) Mediterranean bioconstructions along the italian coast. Adv Mar Biol 79:61-136. https://doi.org/10.1016/bs.amb. 2018.05.001

Judilla RJ, Jauod J, Capili E, Soriano Jr M (2012) Teardrop - a rapid reef mosaicing tool for coastal communitirs. Proceedings of the 12th International Coral Reef Symposium. Cairns (Australia), pp 254-258.

Kipson S, Fourt M, Teixidó N, Cebrian E, Casas E, Ballesteros E, Zabala M, Garrabou J (2011) Rapid biodiversity assessment and monitoring method for highly diverse benthic communities: A case study of mediterranean coralligenous outcrops. PLoS One 6:11-13. https://doi.org/10.1371/journal.pone.0027103

Kulkarni AV, Jagtap JS, Harpale VK (2013) Object recognition with ORB and its implementation on FPGA. Int $\mathbf{J}$ Adv Comput Res 3:164

Li Y, Randall CJ, van Woesik R, Ribeiro E (2019) Underwater video mosaicing using topology and superpixel-based pairwise stitching. Expert Syst Appl 119:171-183. https://doi.org/10.1016/j. eswa.2018.10.041

Lowe DG (2004) Distinctive image features from scale-invariant keypoints. Int J Comput vis 60:91-110

Mancini G, Casoli E, Ventura D, Jona-Lasinio G, Criscoli A, Belluscio A, Ardizzone GD (2019) Impact of the Costa Concordia shipwreck on a Posidonia oceanica meadow: A multi-scale assessment from a population to a landscape level. Mar Pollut Bull 148:168-181. https://doi.org/10.1016/j.marpol bul.2019.07.044

Marre G, Deter J, Holon F, Boissery P, Luque S (2020) Fine-scale automatic mapping of living Posidonia oceanica seagrass beds with underwater photogrammetry. Mar Ecol Prog Ser 643:63-74

Marre G, De Almeida Braga C, Ienco D, Luque S, Holon F, Deter J (2020) Deep convolutional neural networks to monitor coralligenous reefs: Operationalizing biodiversity and ecological assessment. Ecol Inform 59:101110. https://doi.org/10.1016/j. ecoinf.2020.101110

Marre G, Holon F, Luque S, Boissery P, Deter J (2019) Monitoring marine habitats with photogrammetry: A cost-effective, accurate, precise and high-resolution reconstruction method. Front. Mar. Sci. 6:1-15. https://doi.org/10.3389/fmars.2019.00276

Martin CS, Giannoulaki M, De Leo F, Scardi M, Salomidi M, Knitweiss L, Pace ML, Garofalo G, Gristina M, Ballesteros E, Bavestrello G, Belluscio A, Cebrian E, Gerakaris V, Pergent G, Pergent-Martini C, Schembri PJ, Terribile K, Rizzo L, Ben Souissi J, Bonacorsi M, Guarnieri G, Krzelj M, Macic V, Punzo
E, Valavanis V, Fraschetti S (2014) Coralligenous and maërl habitats: Predictive modelling to identify their spatial distributions across the Mediterranean Sea. Sci Rep 4:1-8. https://doi. org/10.1038/srep05073

Meadows PS, Meadows A, Murray JMH (2012) Biological modifiers of marine benthic seascapes: Their role as ecosystem engineers. Geomorphology 157-158:31-48. https://doi.org/10.1016/j.geo morph.2011.07.007

Montefalcone M, Morri C, Bianchi CN, Bavestrello G, Piazzi L (2017) The two facets of species sensitivity: Stress and disturbance on coralligenous assemblages in space and time. Mar Pollut Bull 117:229-238. https://doi.org/10.1016/j.marpol bul.2017.01.072

Murtiyoso A, Grussenmeyer P, Börlin N, Vandermeerschen J, Freville T (2018) Open source and independent methods for bundle adjustment assessment in close-range UAV photogrammetry. Drones 2:1-18. https://doi.org/10.3390/drones2010003

Palma M, Casado MR, Pantaleo U, Pavoni G, Pica D, Cerrano C (2018) SfM-based method to assess gorgonian forests (Paramuricea clavata (Cnidaria, Octocorallia)). Remote Sens 10(7):1154. https://doi.org/10.3390/rs10071154

Palma M, Magliozzi C, Rivas Casado M, Pantaleo U, Fernandes J, Coro G, Cerrano C, Leinster P (2019) Quantifying coral reef composition of recreational diving sites: A structure form motion approach at seascape scale. Remote Sens 11:3027. https://doi. org/10.3390/rs 11243027

Park JY, Choi JY, Jeong EY (2011) Applying an underwater photography technique to nearshore benthic mapping: A case study in a rocky shore environment. J Coast Res 64:1764-1768

Parravicini V, Morri C, Ciribilli G, Montefalcone M, Albertelli G, Bianchi CN (2009) Size matters more than method: Visual quadrats vs photography in measuring human impact on Mediterranean rocky reef communities. Estuar Coast Shelf Sci 81:359-367. https://doi.org/10.1016/j.ecss.2008.11.007

Parravicini V, Micheli F, Montefalcone M, Villa E, Morri C, Bianchi CN (2010) Rapid assessment of epibenthic communities: A comparison between two visual sampling techniques. J Exp Mar Bio Ecol 395:21-29. https://doi.org/10.1016/j.jembe.2010.08. 005

Penna M, Gennaro P, Bacci T, Trabucco B, Cecchi E, Mancusi C, Piazzi L, Rende FS, Serena F, Cicero AM (2018) Multiple environmental descriptors to assess ecological status of sensitive habitats in the area affected by the Costa Concordia shipwreck (Giglio Island, Italy). J Mar Biol Assoc United Kingdom 98:51-59. https://doi.org/10.1017/S0025315417001485

Pergent G, Monnier B, Clabaut P, Gascon G, Pergent-Martini C, Valette-Sansevin A (2017) Innovative method for optimizing Side-Scan Sonar mapping: The blind band unveiled. Estuar Coast Shelf Sci 194:77-83

Piazzi L, Balata D, Pertusati M, Cinelli F (2004) Spatial and temporal variability of Mediterranean macroalgal coralligenous assemblages in relation to habitat and substratum inclination. Bot Mar 47: 105-115. https://doi.org/10.1515/BOT.2004.010

Piazzi L, Cecchi E, Gennaro P, Penna M, Trabucco B, Ceccherelli G (2019) Spread of non-indigenous macroalgae and disturbance: Impact assessment of the Costa Concordia shipwreck (Giglio Island, Italy) using the ALEX index. Ocean Coast Manag 183:104999. https://doi.org/10.1016/j.ocecoaman.2019.104999

Piazzi L, La Manna G, Cecchi E, Serena F, Ceccherelli G (2016) Protection changes the relevancy of scales of variability in coralligenous assemblages. Estuar Coast Shelf Sci 175:62-69. https://doi.org/10.1016/j.ecss.2016.03.026

Piazzi L, Gennaro P, Cecchi E, Serena F, Bianchi CN, Morri C, Montefalcone $M$ (2017) Integration of ESCA index through the use of sessile invertebrates. Sci Mar 81(2): 283-290. https://doi. org/10.3989/scimar.04565.01B 
Piazzi L, Gennaro P, Montefalcone M, Bianchi CN, Cecchi E, Morri C, Serena F (2019) STAR: An integrated and standardized procedure to evaluate the ecological status of coralligenous reefs. Aquat Conserv Mar Freshw Ecosyst 29:189-201. https://doi.org/ 10.1002/aqc. 2983

Regoli F, Pellegrini D, Cicero AM, Nigro M, Benedetti M, Gorbi S, Fattorini D, D'Errico G, Di Carlo M, Nardi A, Gaion A, Scuderi A, Giuliani S, Romanelli G, Berto D, Trabucco B, Guidi P, Bernardeschi M, Scarcelli V, Frenzilli G (2014) A multidisciplinary weight of evidence approach for environmental risk assessment at the Costa Concordia wreck: Integrative indices from Mussel Watch. Mar Environ Res 96:92-104. https://doi. org/10.1016/j.marenvres.2013.09.016

Van Rein H, Schoeman DS, Brown CJ, Quinn R, Breen J (2012) Development of low-cost image mosaics of hard-bottom sessile communities using SCUBA: Comparisons of optical media and of proxy measures of community structure. J Mar Biol Assoc United Kingdom 92:49-62. https://doi.org/10.1017/ S0025315411000233

Rende SF, Irving AD, Bacci T, Parlagreco L, Bruno F, De Filippo F, Montefalcone M, Penna M, Trabucco B, Di Mento R, Cicero AM (2015) Advances in micro-cartography: A two-dimensional photo mosaicing technique for seagrass monitoring. Estuar Coast Shelf Sci 167:475-486. https://doi.org/10.1016/j.ecss.2015.10. 029

Robert K, Huvenne VAI, Georgiopoulou A, Jones DOB, Marsh L, Carter DOG, Chaumillon L (2017) New approaches to highresolution mapping of marine vertical structures. Sci Rep 7:1-14. https://doi.org/10.1038/s41598-017-09382-z

Rosten E, Drummond T (2006) Machine learning for high-speed corner detection. European Conference on Computer Vision. Springer, New York, pp 430-443.

Royer JP, Nawaf MM, Merad D, Saccone M, Bianchimani O, Garrabou J, Ledoux JB, Lopez-Sanz A, Drap P (2018) Photogrammetric surveys and geometric processes to analyse and monitor red coral colonies. J Mar Sci Eng 6(2):42. https:// doi.org/10.3390/jmse6020042

Sartoretto S, Schohn T, Bianchi CN, Morri C, Garrabou J, Ballesteros E, Ruitton S, Verlaque M, Daniel B, Charbonnel E, Blouet S, David R, Féral JP, Gatti G (2017) An integrated method to evaluate and monitor the conservation state of coralligenous habitats: the INDEX-COR approach. Mar Pollut Bull 120:222-231. https://doi.org/10.1016/j.marpolbul.2017.05.020

Sim J, Wright CC (2005) The kappa statistic in reliability studies: Use, interpretation, and sample size requirements. Phys Ther $85: 257-268$

Sini M, Garrabou J, Trygonis V, Koutsoubas D (2019) Coralligenous formations dominated by Eunicella cavolini (Koch, 1887) in the NE Mediterranean: Biodiversity and structure. Mediterr Mar Sci 20:174-188

SPA, RAC-UN ENVIRONMENT, MAP, (2019) Updated reference list of marine habitat types for the selection of sites to be included in the national inventories of natural sites of conservation interest in the Mediterranean. UNEP/MAP-SPA/RAC publ, Tunis, p 20
Teixidó N, Casas E, Cebrián E, Linares C, Garrabou J (2013) Impacts on coralligenous outcrop biodiversity of a dramatic coastal storm. PLoS ONE 8:e53742. https://doi.org/10.1371/journal. pone.0053742

Toniolo C, Di Sotto A, Di Giacomo S, Ventura D, Casoli E, Belluscio A, Nicoletti M, Ardizzone GD (2018) Seagrass Posidonia oceanica (L.) Delile as a marine biomarker: A metabolomic and toxicological analysis. Ecosphere 9(3): e02054. https://doi.org/ 10.1002/ecs 2.2054

Tribot AS, Mouquet N, Villéger S, Raymond M, Hoff F, Boissery P, Holon F, Deter J (2016) Taxonomic and functionnal diversity increase the aesthetic value of coralligenous reefs. Sci Rep 6:34229. https://doi.org/10.1038/srep34229

Trygonis V, Sini M (2012) photoQuad: a dedicated seabed image processing software, and a comparative error analysis of four photoquadrat methods. J Exp Mar Bio Ecol 424-425:99-108. https://doi.org/10.1016/j.jembe.2012.04.018

Valisano L, Palma M, Pantaleo U, Calcinai B, Cerrano C (2019) Characterization of North-Western Mediterranean coralligenous assemblages by video surveys and evaluation of their structural complexity. Mar Pollut Bull 148:134-148. https://doi.org/10. 1016/j.marpolbul.2019.07.012

Vasilijevic A, Buxton B, Sharvit J, Stilinovic N, Nad D, Miskovic N, Planer D, Hale J, Vukic Z (2015) An ASV for coastal underwater archaeology: The Pladypos survey of Caesarea Maritima, Israel. Proceedings of MTS/IEEE OCEANS'15 Conference, , Genova (Italy), pp 1-7

Ventura D, Dubois SF, Bonifazi A, Jona Lasinio G, Seminara M, Gravina MF, Ardizzone G (2021) Integration of close-range underwater photogrammetry with inspection and mesh processing software: a novel approach for quantifying ecological dynamics of temperate biogenic reefs. Remote Sens Ecol Conserv 7(2): 169-186. https://doi.org/10.1002/rse2.178

Wilder KE (2009) Photography and science. Reaktion Books Ltd, London

Williams ID, Couch CS, Beijbom O, Oliver TA, Vargas-Angel B, Schumacher BD, Brainard RE (2019) Leveraging automated image analysis tools to transform our capacity to assess status and trends of coral reefs. Front Mar Sci 6:222

Xing C, Huang J (2010) An improved mosaic method based on SIFT algorithm for UAV sequence images. International Conference On Computer Design and Applications. Qinhuangdao (China), pp 414-417.

Zapata-Ramírez PA, Scaradozzi D, Sorbi L, Palma M, Pantaleo U, Ponti M, Cerrano C (2013) Innovative study methods for the Mediterranean coralligenous habitats. Adv Oceanogr Limnol 4:102-119. https://doi.org/10.1080/19475721.2013.849758

Zhao J, Zhang X, Gao C, Qiu X, Tian Y, Zhu Y, Cao W (2019) Rapid mosaicking of unmanned aerial vehicle (UAV) images for crop growth monitoring using the SIFT algorithm. Remote Sens 11:1226. https://doi.org/10.3390/rs11101226

Publisher's Note Springer Nature remains neutral with regard to jurisdictional claims in published maps and institutional affiliations. 